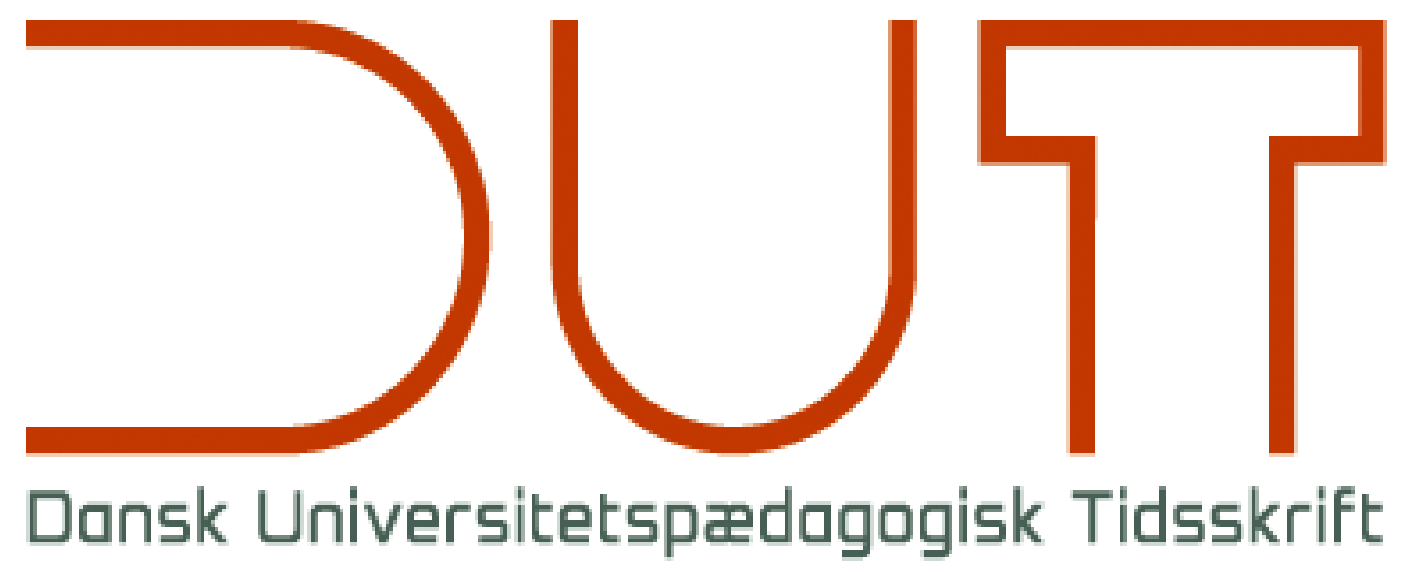

Tema

Undervisningens teknologier og teknikker

Årgang 15 nr. 28 / 2020

Titel

"Vi er rigtig meget ens": Peer-dynamik i samarbejdet mellem specialeskrivende par

Forfattere

Sidetal

Udgivet af

URL

Helle Merete Nordentoft, Tine Wirenfelt Jensen, Søren Smedegaard Bengtsen

$107-123$

Dansk Universitetspædagogisk Netværk, DUN

> http://dun-net.dk/

Betingelser for brug af denne artikel

(c) Copyright
Denne artikel er omfattet af ophavsretsloven, og der må citeres fra den. Følgende betingelser skal dog være opfyldt:

- Citatet skal være i overensstemmelse med "god skik"

- Der må kun citeres „i det omfang, som betinges af formålet“

- Ophavsmanden til teksten skal krediteres, og kilden skal angives ift. ovenstående bibliografiske oplysninger.

DUT og artiklens forfatter 


\title{
"Vi er rigtig meget ens": Peer-dynamik i samarbejdet mellem specialeskrivende par
}

\author{
Helle Merete Nordentoft ${ }^{\mathrm{a}, 1}$, Tine Wirenfelt Jensen ${ }^{\mathrm{b}}$, Søren Smedegaard Bengtsen ${ }^{c}$ \\ aDanmarks institut for Pædagogik og Uddannelse - Uddannelsesvidenskab, København \\ ${ }^{b}$ METoDo og SDU Universitetspædagogik, Syddansk Universitet \\ 'Center for Undervisningsudvikling og Digitale Medier, Aarhus Universitet
}

Videnskabelig artikel, fagfællebedømt

\begin{abstract}
Fra 2015-2018 er antallet af parspecialer på Faculty of Arts (Arts) på Aarhus Universitet steget med næsten 300\%. Der foreligger ikke systematisk forskning i, hvorfor der er en stigning, eller hvilke implikationer denne ændrede praksis har for hverken de studerendes læring eller vejledningen. Med afsæt i en Bakhtinsk forståelse af dialog undersøger vi, hvordan specialepars peer-dynamikker influerer på deres oplevelse af samarbejds- og læreprocesser. Empirien stammer fra et longtitudionelt studie, hvor fire specialepar har reflekteret på sammen på deres smartphones sammen tre gange i deres skriveproces. Analyserne viser, hvordan parrene i deres dialog løbende forhandler deres relation og faglighed, uden at de tilsyneladende undersøger de spændinger, som opstår undervejs i skriveforløbet. Vi konkluderer, at det kan øge de studerendes selvstændighed at skrive speciale sammen i par, da parret i et forpligtende samarbejde må træffe en række valg sammen, men tosomheden er også sårbar og kan blive et værn mod at undersøge den flerstemmighed, der i en Bakhtinsk forståelse er en forudsætning for læring.
\end{abstract}

\section{Indledning}

Flere og flere studerende vælger at skrive speciale sammen i par. Blot inden for de sidste tre år (2015-2018) er antallet af parspecialer på Faculty of Arts (Arts) på Aarhus Universitet steget fra 32 parspecialer i 2015 til 124 parspecialer i 2018, hvilket er en stigning på cirka 300\% (se Tabel 1). Institut for Uddannelse og Pædagogik (DPU) har det største antal parspecialer og desuden den mest markante stigning af alle institutter på Arts. På DPU er antallet af parspecialer steget fra 55 i 2016 til 83 i 2018, med topscoren Pædagogisk Psykologi med en stigning fra ét parspeciale i 2015 til 62 (!) parspecialer i 2018. Der foreligger ingen systematisk forskning i, hvorfor der er en stigning eller hvilke implikationer denne ændrede praksis har for hverken de studerendes læring eller vejledningen. Stigningen i parspecialer kan måske forklares ved, at studerende på danske universiteter efter ændringerne i universitetsloven fra 2011 er underlagt større grad af kontrol og styring af deres studie- og læringsprocesser, som betyder, at de har ændret studieadfærd (Degn \& Sørensen, 2015; Sarauw \& Madsen, 2016). Fremdriftsreformen fra 2013 har medført en nedskæring på den individuelle vejledning, som har været almindelig praksis igennem mange år især på humaniora. Flere forskere peger endvidere på, at reformerne har medført, at de studerende har udviklet nye strategier og er blevet mere instrumentelle $\mathrm{i}$ arbejdet med at gennemføre deres studier på normeret tid (Sarauw \& Madsen, 2016), hvor deres fokus er flyttet fra opnåelse af ny viden til, hvordan de bedst muligt opfylder målkravene til eksamen og på denne måde 'gamer' systemet (Nørgård,

${ }^{1}$ Kontakt: hmn@edu.au.dk 
Toft-Nielsen, \& Whitton, 2016). I forlængelse af disse uddannelsestiltag har universitetet været optaget af at kvalificere og gentænke organisering af specialevejledningen, når der er færre ressourcer til rådighed. Universiteterne har i stigende grad fokuseret på at styrke kollektive og digitaliserede formater for vejledning som Kollektiv Akademisk Vejledning (Nordentoft et al., 2019; Nordentoft, Thomsen, \& Wichmann-Hansen, 2013) og klyngevejledning (Jensen, 2015), hvor studerende vejledes i mindre grupper, samt distribueret vejledning $i$ form af peer feedback (Hvass \& Heger, 2018) og nye tilgange til online vejledning (Bengtsen, Mathiasen, \& Dalsgaard, 2015; Bengtsen \& Nørgård, 2018).

Tabel 1. Arts Studier, stigningen i parspecialer 2019.

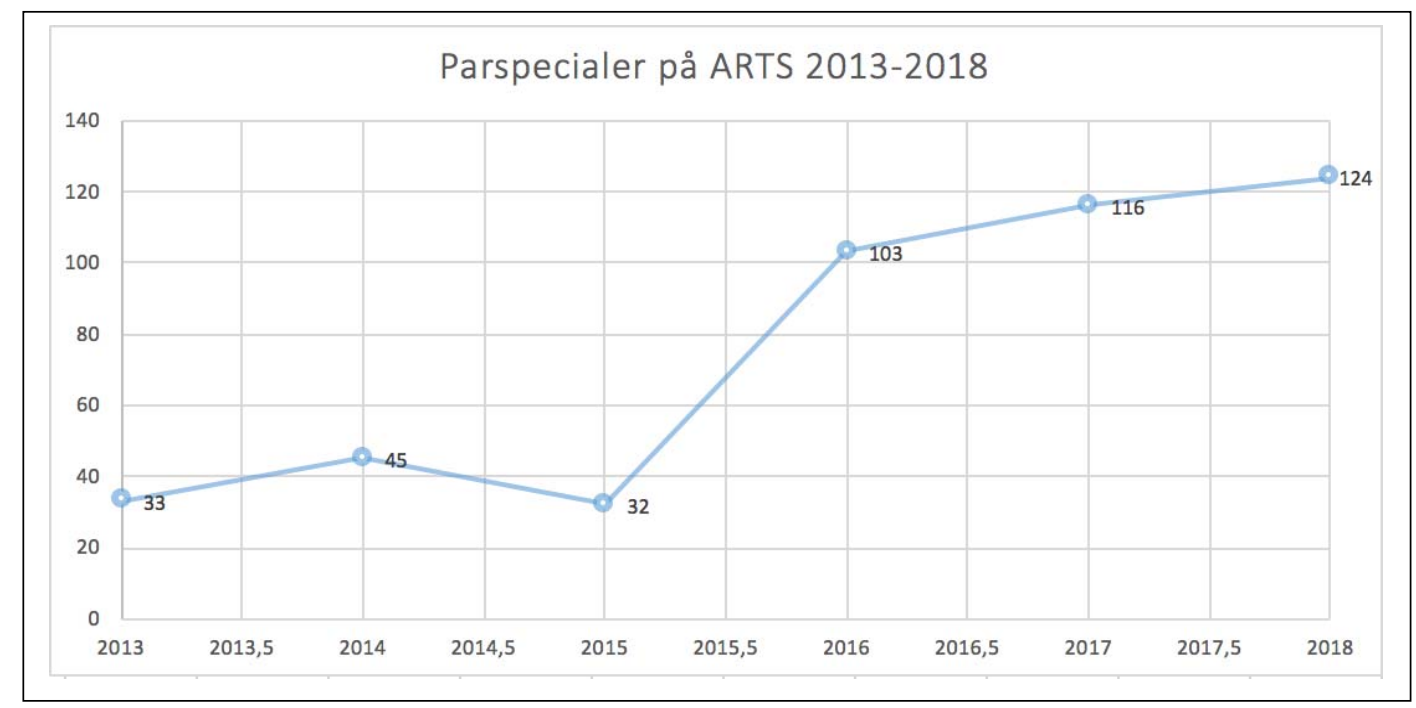

Kilde: Arts studier, Aarhus Universitet

Kollektiv og online vejledning på danske universiteter er, ligesom den individuelle specialevejledning, veldokumenteret gennem de sidste ti års forskning (Andersen \& Jensen, 2007a, 2007b; Bengtsen, 2012; H. N. Jensen, 2010). Den forskning, der kommer tættest på forskning i parspecialer, er undersøgelser af studerendes peer feedback forløb (Hvass \& Heger, 2018), der dog udelukkende fokuserer på kommunikationen omkring det skriftlige produkt gennem en struktureret samtaleform - og ikke på udarbejdelsen af en fælles opgave som et samarbejdsforløb eller en samarbejdsrelation. Den internationale forskning har undersøgt parsamarbejdet i en mere uforpligtende forstand - de såkaldte 'buddy systems' eller 'makkerordninger' (Cryer, 2006), hvor studerende ikke skriver sammen, men blot støtter hinanden i skriveprocessen. De er derfor ikke forpligtede i forhold til at skulle levere et fælles produkt. Til trods for den øgede interesse i forskellige former for distribueret vejledning og feedback i udviklingen af peer-miljøer, peer feedback og peer-støtte (Boud \& Lee, 2005; Dysthe, Samara, \& Westrheim, 2006) mangler vi stadig viden om specialeskrivning i par, og om hvad denne konstellation har af implikationer for de studerendes vejlednings- og samarbejdsproces.

I denne artikel præsenterer vi et longtitudionelt studie med empiri fra DPU, hvor datakorpus består af 11 lydoptagelser af fire pars fælles mundtlige refleksioner tre gange i deres specialeforløb i foråret 2018. Teoretisk tager vi afsæt i Bakhtins dialogforståelse (Bakhtin, 1981) for at undersøge, hvordan parrene oplever deres samarbejds- og læreprocesser i specialeskrivningsforløbet. 


\section{Teoretisk afsæt}

Litteraturteoretikeren Mikhail Bakhtins dialogforståelse danner teoretisk afsæt for udforskningen af de studerendes dialoger og læreprocesser (Bakhtin, 1981). I en fænomenologisk forståelse af dialog ses dialogen som et møde mellem to ligeværdige mennesker, hvor parterne i dialogen arbejder sammen på at skabe en fælles forståelse (Buber, 2004; Nordentoft \& Olesen, 2014; Phillips, 2011a, 2011b). Bakhtin tilbyder en mindre præskriptiv og mere beskrivende forståelse af dialog. I Bakhtins optik er dialogen et møde mellem mennesker, som udveksler forskellige udsagn, og hvor sproget har en flerstemmig karakter. En stemme i denne sammenhæng er ikke det samme som en fysisk stemme eller et konkret udsagn, men et udtryk for den værdimæssige position, et standpunkt bygger på. I dialogen formes hver stemme i en kontinuerlig, uendelig og emergerende proces, som veksler mellem forventningen til og responsen på andre stemmer (Phillips, 2011b), og det er en pointe, at denne flerstemmighed rummer kimen til betydningsdannelse og læring. Betydning og meningsskabelse er således ikke et kognitivt og individuelt fænomen, der, som i fænomenologien, centrerer sig mod en tosomhed og en 'lukket' samtalekreds. Derimod skabes og genskabes betydning i en socialt og kulturelt forgrenet aktiv og dialogisk spændingsfyldt forståelsesproces imellem mennesker i lyset af "forskellige og ofte modscetningsfulde og konkurrerende stemmer" (Phillips, 2011a, s. 172).

Bakhtin beskriver, hvordan denne betydningsdannelse finder sted i samspillet og spændingsforholdet mellem to samtidige, modsatrettede og konkurrerende tendenser: Den centripetale tendens i retningen af enhed og konsensus og den centrifugale tendens i retningen af forskel, som betyder, at der åbnes for forskellige stemmer og vidensformer. Måske bidrager forskellene til at skabe uenighed og dissensus i dialogen, men uden spændinger kan betydningsdannelse ikke finde sted (Dalgaard, Johannsen, Kristiansen \& Bloch-Poulsen, 2013; Phillips, 2011b). Hvornår og hvordan der lukkes op og ned for forskellige stemmer i dialogen mellem de studerende, må antages at have betydning for deres samarbejde og læringsproces.

I dette teoretiske perspektiv kan mødet mellem de to studerende, som skriver speciale sammen, betegnes som et møde mellem to mennesker, som bringer forskellige og poentielt konkurrerende stemmer i form af indsigter, meninger og erfaringer med sig ind i dialogen. De studerende kan have forskellige indstillinger til, hvor intenst der skal arbejdes med specialet: mellem at knokle for at blive færdig til tiden og tilpasse sig den herskende diskurs - eller måske tage mere fri og slappe af for dermed at risikere ikke at aflevere til tiden. Endvidere kan det også være en udfordring at finde en balance i forskellen mellem at være en god veninde og kritisk faglig sparringspartner.

Dialog for Bakhtin indbærer også en respekt for det uforløste potentiale, den anden part rummer, da dialogen er uendelig i forhandlingen mellem fortidige, nutidige og fremtidige stemmer. Dialogen er således ikke blot uendelig med også "unfinalizable", som kan oversættes til "uafsluttelig" (Frank, 2005). Det er her en etisk pointe, at parterne i en dialog aldrig bør "finalize" hinanden, da dette implicerer, at man fremsætter en determinerende vurdering af, hvordan den anden er som person. I modsætning til denne determinisme er dialog funderet $\mathrm{i}$ en respektfuld åbenhed overfor den andens mulighed for altid at kunne "become some other than who ever she or he is" (Frank, 2005). Denne dialogiske diskurs står i modsætning til den monologiske og determinerende diskurs, som er fremherskende i institutionelle og neoliberale kontekster. En diskurs, som er afgørende for at opnå professionel status, og som indgår i 
den formelle bedømmelse af et speciales akademiske kvaliteter. Spørgsmålet er, hvordan de studerende beskriver deres samarbejde om at bevare en dialogisk åbenhed i mødet med deres forskellige stemmer i en monologisk orienteret kontekst.Vi undersøger, hvordan de taler om og medierer de forskelle, der opstår mellem de stemmer, som kommer til udtryk i dialogen. Bliver disse forskelle genstand for en fælles undersøgelse og drivkraft i en læreproces i forhold til at blive klogere på, hvad de konkret handler om, eller bliver der lukket ned for dem i deres dialog?

\section{Metode}

De fire specialeskrivende pars mundtlige refleksioner er lavet med afsæt i en spørgeguide, som er udviklet af forskergruppen. Data er indsamlet igennem forårssemesteret 2018, hvor hvert par var inviteret til at optage tre refleksioner: Én i begyndelsen af specialeprocessen, én halvvejs gennem deres specialeskrivningsforløb og endelig én efter aflevering eller karakterafgivelse og feedback. De studerende skrev speciale på DPU, og parrene har optaget deres refleksioner på en smartphone og efterfølgende indsendt lydfilen, hvorefter lydfilerne blev transskriberet.

Tabel 2. Oversigt over datamateriale

\begin{tabular}{|l|l|l|l|}
\hline Par & 1-Refleksion & 2-Refleksion & 3-Refleksion \\
\hline $\begin{array}{l}\text { Jeanett og } \\
\text { Sanne }\end{array}$ & 26,59 & 33,57 & 43,45 \\
\hline Lotte og Sille & 26,39 & 35,51 & 20,44 \\
\hline Karin og Anne & 15,26 & 19,50 & 32,06 \\
\hline Irene og Maja & 5,25 & 7,09 & Ikke indsendt \\
\hline Minutter totalt & 73,49 & 95,67 & 95,95 \\
\hline
\end{tabular}

Som tabel 2 viser, var der et par, som producerede meget korte refleksioner og desuden ikke lavede den sidste refleksion. Måske skyldes det, at dette par havde større faglige udfordringer og endte med ikke at aflevere til tiden. Specialeforløbet trak således ud og var udfordrende for parret, ligesom de først fik deres endelige karakter efter sommerferien.

\section{Spørgeguide}

Inden hver af de tre refleksioner har de studerende fået tilsendt en række spørgsmål i form af en spørgeguide. Spørgsmålene var kronologiske og bygget op omkring tre hovedtematikker for at få indblik i parrenes skriveproces og de oplevelser og følelser, som er forbundet med den. Konkret betyder det, at der først spørges til historikken omkring, hvorfor parrene har valgt at skrive sammen, og dernæst, hvordan de planlægger og konkret samarbejder, herunder hvornår og hvor meget de mødes, og hvordan de arbejder med at give hinanden feedback. Spørgsmålene er udformet med to formål. 1) At få indsigt i parrenes baggrund samt deres motiver for at arbejde sammen. 2) At lægge op til samtaler, som giver indblik i parrenes dynamik, herunder hvordan de navigerer i forhold til centripetale og centrifugale tendenser i dialogen. 


\section{Valg af dataproduktionsmetode}

Dataproduktionsmetoden er udviklet $\mathrm{i}$ og inspireret af et tidligere studie (Nordentoft \& Jensen, 2017). Der er flere forhold, som betinger vores valg: For det første antager vi, at de studerendes samtaler uden indblanding fra en forsker eller vejledere resulterer i mere ligeværdige, autentiske og spontane kommentarer, end hvis vi var til stede og påvirkede parrenes samtaler. Desuden kan parrene tale sammen, når det passer dem. De parvise dialoger har også den forskningsmetodiske fordel, at de kan give et indblik i, hvordan parrene taler sammen og relaterer sig til hinanden. Deres dialoger belyser nemlig ikke kun det emne, som parret taler om, men også, hvordan de taler om de forskellige emner og positionerer sig i forhold til både emnet og hinanden. Endelig ser vi det tidsmæssige sammenfald mellem refleksionerne og vejledningen som en styrke i empirien, da det giver et klart billede af, hvordan de studerende oplever lærings- og skriveprocessen, mens de er midt i den (Pedersen, Albrechtsen \& Jensen, 2013). Begrænsningen i dette metodiske valg er dog, at vi som forskere ikke får mulighed for at introducere andre stemmer i dialogen og dermed facilitere en kritisk refleksiv stillingtagen, som ikke nødvendigvis optræder i de studerendes refleksioner. Yderligere skal det bemærkes, at selvom undersøgelsen er et longitudionelt studie, har vores fokus ikke været på, hvordan den tidslige proces former dialogen og erkendelsen mellem parrene (som dog synes at opnå større grad af refleksivitet, som processen skrider frem). Vi har valgt at fokusere på, hvordan samarbejdet opleves og italesættes på tværs af optagelserne og dermed igennem hele specialeprocessen, med intentionen om at opnå en helhedsforståelse af parsamarbejdet.

\section{Forskningsetiske overvejelser}

Tre af parrene er blevet vejledt af en af forfatterne, det sidste par af en anden vejleder på DPU. At tre af parrene er inviteret til at deltage i undersøgelsen af deres vejleder, kan have mulige implikationer set fra både de studerendes og forfatterens perspektiv.

Alle par har underskrevet et informeret samtykke og er lovet anonymitet. For at undgå, at de par, som en af forfatterne vejledte, følte sig presset til at være positive overfor vejledningen, har vi i informationen om projektet til de studerende i understreget, at fokus ikke er på specialevejledning, men på den måde, som parret har arbejdet sammen i skriveprocessen. Desuden har forfatteren som vejleder pointeret, at det er i orden af være kritisk, da meningen med projektet er at blive klogere på, hvilke faktorer, der har betydning for par iskriveprocessens forløb. Det har altså ikke været formålet at undersøge, om de studerende var tilfredse med vejledningen, eller om de har forstået et bestemt fagligt indhold.

I projektet måtte forfatteren, som var vejleder, således navigere imellem tre forskellige positioner: vejleder, bedømmer og forsker. I forvejen kan vejleder- og bedømmerrollen opleves som modsatrettede positioner, hvilket øger kompleksiteten i interaktionen med de studerende. Når dertil lægges en position som forsker, er der brug for at overveje, hvordan dette virvar af skiftende positioner kan håndteres i en forskningsproces (Berger, 2015; Macbeth, 2001). For at kunne navigere i denne kompleksitet og styrke den kritisk refleksive proces med at få øje på, hvad der er på spil mellem parrene i deres samarbejdsproces, inviterede forfatteren to andre forskere i projektet. Lige fra formulering af spørgsmålsguide til analysefasen har alle trin i forskningsprocessen været en fælles proces. Dette muliggjorde at inddrage forskerkollegerne som sparringspartner undervejs, når det blev udfordrende at navigere imellem de mange positioner, ligesom det har givet mulighed for at udfordre antagelser. Forfatteren/vejlederen har ført logbog gennem hele processen og herigennem løbende reflekteret 
over både vejlednings- og forskningsaspektet samt gennemført et afsluttende interview med forfatterkollegaerne om egen rolle i processen. Endelig ventede forfatteren/vejlederen med at lytte til interviewene, indtil bedømmelsen var afsluttet.

\section{Analysestrategi}

Vi har operationaliseret Bakthins teori og begreber $i$ analysen med inspiration fra Philips (Phillips, 2011a), som formulerer en række spørgsmål, man kan stille til tekstmaterialet. Vi har udvalgt to analysespørgsmål, der fokuserer på samspillet mellem centripetale og centrifugale tendenser i parrenes dialoger:

- I hvilken grad, hvornår og hvordan åbnes der op for stemmer, som skaber en mangfoldighed af forskellige vidensformer (den centrifugale tendens)?

- I hvilken grad, hvornår og hvordan "lukkes der ned", således at der skabes et entydigt "vi" og entydige vidensformer (den centripetale tendens)?

I analysen har vi inddraget metodiske greb fra den konstruktivistiske udgave af grounded theory (Charmaz, 2014), som er velegnet til at sikre en forankring af analysen i data. Der er altså ikke tale om, at grounded theory udgør en samlet ramme for analysen, men at der anvendes udvalgte greb, der er kompatible med analysens hermeneutiske forståelses- og forklaringsramme. Med afsæt i Philips' spørgsmål har vi i analysen produceret en række memoer til hvert enkelt af de transskriberede interviews (Charmaz, 2014). På baggrund af en fælles analyse af de transskriberede interviews og disse memos har vi identificeret en række temaer (Charmaz, 2014), som de to tendenser og samspillet imellem dem synliggøres i forhold til (se tabel 3).

Tabel 3. Oversigt over koder og temaer

\begin{tabular}{|l|l|}
\hline Kode & Tema \\
\hline $\begin{array}{l}\text { Gensidige opfattel- } \\
\text { ser af karaktertræk }\end{array}$ & $\begin{array}{l}\text { Spændinger/forhandling mellem deres beskrivelser af egne/hinandens } \\
\text { karaktertræk som studerende og betydningen for det fælles samarbej- } \\
\text { de. }\end{array}$ \\
\hline Tid & Spændinger imellem din tid, min tid og vores tid. \\
\hline Teksten & $\begin{array}{l}\text { Teksten som møde- og skillested. Forskelle og evt. spændinger mellem, } \\
\text { hvordan de hver især arbejder med teksten. }\end{array}$ \\
\hline $\begin{array}{l}\text { Hygge og/eller ar- } \\
\text { bejde }\end{array}$ & Forhold og evt. spænding mellem faglig og personlig relation. \\
\hline Steder og aktiviteter & $\begin{array}{l}\text { Forhold/spændinger mellem dit og mit sted (bolig), universitetet og } \\
\text { hvordan de indgår i skriveprocessen. }\end{array}$ \\
\hline
\end{tabular}




\begin{tabular}{|c|c|}
\hline Omverdenen & $\begin{array}{l}\text { Parrets relation til deres omverden i forhold til } \\
\text { - } \\
\text { - } \\
\text { - } \quad \text { vejlederen. } \\
\text { sociale/familiære sammenhænge udenfor studiet i } \\
\text { specialeprocessen. }\end{array}$ \\
\hline
\end{tabular}

\section{Analyse}

I det følgende analyserer vi dialogen i parskrivningssamarbejdet med inddragelse af de temaer, der præsenteres i Tabel 3. Analysen præsenteres i to overordnede dele: For det første med fokus på dialogen mellem parskriverne - den intersubjektive dimension. I denne del fokuserer vi på parrets dialog om, hvordan de opfatter og forholder sig til hinanden og deres samarbejde. Vi inkluderer her ikke her deres arbejde omkring teksten (det er et selvstændigt tema, vi behandler i en kommende artikel). Efter vi har udfoldet dialogen mellem parret, fokuserer vi på deres dialog med omverdenen.

\section{Dialogen mellem parskriverne}

Faglige og personlige stemmer

I parrenes dialoger kommer både faglige, personlige og private stemmer i spil og influerer på dynamikken mellem de centripetale og centrifugale tendenser i parrenes samtale om deres skriveproces.

Alle fire par har skrevet sammen før, og flere af dem har skrevet stort set alle deres tidligere opgaver sammen. Tre er parrene har en privat relation til hinanden og er "tætte venner". Et par bor sammen, og alle par har fælles studievenner og deltager i sociale aktiviteter sammen. Deres refleksioner giver et indblik i fællesskaber, der rækker langt ud over et fagligt samarbejde: Der bages kage til fælles gæster under en interviewsamtale, der tales om fælles maling af lejligheder, fælles rejser, samtaler om personlige forhold som for eksempel familie og sygdom. Den personlige, private og faglige relation flyder sammen. Anne bemærker meget sigende, hvordan: Vi er personlige $i$ vores faglighed og faglige $i$ vores personlighed, og Sanne og Jeanett beskriver sig som "meget tætte" og rigtig meget ens. De citerer studievenner for at se dem som en form for enhed og sige Nå ja, men Jeanett og Sanne, man kan ikke komme mellem Jeanett og Sanne eller sådan noget.

Sille og Lotte har fælles hobbyer og fritidsinteresser, de deler humor, og begge udtrykker et behov for en form for nærhed, som betyder, at de fx ikke bare går hver til sit i pauserne. De er desuden meget anerkendende i deres måde at tale sammen på. I det første interview beskriver de deres relation således:

Lotte: Det har også noget med den ydmyghed at gøre. Altså vi er meget lyttende over for det, den anden har uanset om det er fagligt, personligt, om det er noget, der slet har noget med skolen at gøre, så tager vi os tid til, at det er i orden, alle skal vare med i processen.

Sille: Ja. Lige proecis.

Lotte: Alle to. 
Sille: Alle to skal vare med i processen. Ja og så på den måde kan man sige, har cerlighed også fyldt meget, så det er vigtigt for os at vi ved, hvor vi har hinanden.

Deres omtale af sig selv som "alle to" sammen med deres turtagning, hvor de gentager hinandens udsagn, fuldfører hinandens sætninger (og griner på samme tid), viser, hvordan de er emotionelt forbundet med hinanden og kommunikativt synkroniserede, og at de samarbejder om at skabe et fælles "vi". Samme tendens ses, når Karin siger vi laver det hele sammen, hvor Anne ikke supplerer men gentager Karins kommentar i den næste sætning.

De nævnte træk karakteriserer særligt dialogen mellem de første tre par. Det fjerde par, Irene og Maja, italesætter ikke sig selv som et "par" eller som venner på samme måde som de andre. At der alligevel også for dem er tale om en personlig relation, understreges af, at de påpeger, at de taler om det, der "fylder" (for eksempel et dødsfald), har "stor tillid og forståelse" til hinanden og tager til udlandet på fælles skriveophold.

Parrenes nærhed betyder, at uenighed er et udfordrende emne at italesætte for parrene. Parrene undviger dette tema både i deres dialog med hinanden og i deres refleksioner. Således forbinder Lotte og Sille uoverensstemmelser med "uvenskab" i deres sidste refleksion på spørgsmålet om, hvordan de har håndteret uoverensstemmelser, hvor de svarer:

Lotte: Jamen, jeg synes uoverensstemmelser, det er et weird begreb, fordi at sådan lidt, hvad er en uoverensstemmelse, altså sådan graden af den, for jeg synes ikke rigtig, vi som sådan har uoverensstemmelser.

Sille: Nej, hvis det er en diskussion fagligt, så diskuterer vi og argumenterer vi for hver vores synspunkter og så kommer vi jo frem til en faelles løsning, men jeg synes ikke vi har haft uoverensstemmelser altså.

Lotte: Ja. Det synes jeg heller ikke

Sille: Altså, ikke sådan hvor vi har voret uvenner eller.

Lotte: Nej.

Sille: Noget omkring, så det synes jeg faktisk slet ikke, vi har oplevet.

Lotte: Det synes jeg heller ikke. Altså, det har vi aldrig haft.

Sille: Nej.

Lotte: Og det, tror jeg, kommer sig af den respekt, man har for hinanden.

Sille: Ja.

Lotte: Ja og tillid der er.

Sille: Ja.

Karin bemærker, hvordan hun synes, at:

vi er gode til lige sådan hvis vi kan maerke der har voret et eller andet ift. i løbet af dagen at man så lige senere siger sådan, jeg kunne godt maerke du blev irriteret, hvad handlede det om, eller er du ok, skal vi snakke om det eller sådan noget.

Anne: Ja, lige proecis. 
Karin: At det kan godt vare, vi ikke tager den lige praecis idet den opstår, fordi man lige sidder og surmuler, men jeg synes vi er gode til at sige til hinanden, det er jeg ked af, eller er du ok.

Og lidt senere siger Karin:

Karin: Men det er jo også igen fordi, det er jo lige så meget.

Anne: Det personlige.

Karin: Vores venskab vi også gerne vil.

Anne: Bevare.

Parrets udsagn ovenfor kan ses som et eksempel på, hvordan deres personlige kendskab til hinanden synes at være præget af tillid og respekt, hvor de ikke 'finalizer' eller vurderer den anden negativt (Frank, 2005). Der er meget på spil for den enkelte i specialesamarbejdet, for hvis samarbejdet er udfordret, kan det få konsekvenser ikke kun fagligt, men også personligt, socialt og privat. Ikke kun relationen til en studiekammerat sættes på/i spil, men potentielt relationen til en meget tæt veninde og måske en bofælle med en fælles omgangskreds.

Parskriverne går ind i specialeprocessen med en oplevelse af "et entydigt vi" (Phillips, 2011a), et "vi", som det tilsyneladende har stor betydning for dem at fastholde. Denne dynamik gør det nødvendigt for dem at have strategier til at håndtere deres forskellige stemmer og den centrifugale tendens, der kan bidrage til at skabe uenighed og dissensus i dialogen. I de følgende afsnit viser vi, hvordan parret tildeler hinanden komplementære roller og separate vidensdomæner i deres samarbejde, ligesom de anvender hygge og humor som medieringspraksis.

\section{Opstarter eller afslutter? Komplementæere roller i parsamarbejdet}

Når parrene skal tale om deres forskellige styrker og svagheder, gør de en del ud af at beskrive, hvordan de komplementerer hinanden i arbejdet med specialet. Sille er god til at skrive noter ned, når hun læser, det er Lotte ikke. Sille skriver stikord til afsnit som oplæg til diskussion, hvor Lotte skriver hele afsnit. Sille er god til det videnskabsteoretiske, og det er Lotte ikke (ifølge Lotte), men Lotte er god til at lave litteraturliste, siger hun (og så griner hun). Lotte er mere afslappet i sit tempo, mens Sille er hurtig til "at få lavet nogle overskrifter."

Maja og Irene fremhæver også, hvordan de supplerer hinanden og tildeler hinanden faste roller, hvor den ene er "tilrettelægger" og "mere struktureret", mens den anden løbende skriver ideer frem og kan producere tekst på meget på kort tid. Også Sanne og Jeanett har forhandlet sig frem til helt faste roller, hvor den ene er "opstarter" og den anden er "afslutter". De beskriver i det afsluttende interview, hvordan de forholder sig emotionelt til skriveprocessen, og integrerer dette i fortællingen om deres rollefordeling:

Sanne: [...] jeg er nemlig den pessimistiske i starten af specialet, fordi jeg ikke lige kan finde ud af retningen og der er du den optimistiske og i slutningen, der er det mig, der er den optimistiske og du er den pessimistiske.

Jeanett: Ja.

Sanne: Og det ligger jo også i forlaengelse af, at du er en god opstarter og jeg er en god afslutter, ikke. 
Dialogen ovenfor illustrerer den opmærksomhed, parrene har på hinandens emotionelle tilstand, og når den ene part mister energi i arbejdet eller er trist. Karin beskriver, at det er vigtigt, at de kan "hive hinanden op", som med det samme følges op af Annes pointe om, at det er vigtigt, at de kan "loene sig lidt op ad hinanden."

Lige fra starten af specialeprocessen tildeler parrene hinanden bestemte egenskaber og faste roller, som tilsyneladende ikke virker til at blive genforhandlet i løbet af processen. Med andre ord iscenesætter parrene deres indbyrdes forskelle som en fælles fortælling om, at de har kompetencer i hver deres dele af opgaveskriveprocessen. Denne strategi giver parskriverne mulighed for at tildele hinanden styrker og svagheder uden hverken at tabe ansigt eller forrykke balancen imellem dem. De mulige spændinger, der er mellem forskellige stemmer, transformeres til en fortælling om, hvordan de komplementerer hinanden i specialeskrivearbejdet. De forskellige styrker og svagheder kommer derfor også til at underbygge deres valg om at skrive speciale sammen.

Den komplementære strategi indebærer dog også en risiko for at indsnævre parskrivernes læringsrum, hvilket Sanne og Jeanett er bevidste om, når Sanne i det første interview siger, at:

...der er i hvert fald nogle roller, der er givet på forhånd. Det er ikke nogen vi skal til at debattere hver gang, men det er ikke nogen roller, der er så lukkede, at man ikke, hvad kan man sige...

Set i et læringsperspektiv kan denne komplementære opgavedelegering være problematisk. Med rette kan man spørge, om Sanne lærer at google-søge, eller om Jeanett lærer at skabe overblik, når deres partnere har styr på og overtager ansvaret for denne del af arbejdsprocessen? Fastholdelsen af, hvem der laver hvad, kan forhindre, at parret lærer noget om hinandens forskellige styrker. Dermed kan den komplementære fortælling risikere at lukke ned for parternes nysgerrighed på og udforskningen af de forskelle stemmer, som de hver især bidrager med i samarbejdet. I stedet kommer samarbejdet til at fremstå instrumentelt og som en 'velsmurt skrivemaskine', hvor forskellene udnyttes konstruktivt i fremdriften af specialet (Sarauw \& Madsen, 2016). Vurderingen af parrenes specialer viser, at de formår at integrere og sammenfatte forskellige stemmer og styrker i skabelsen af en helstøbt specialeafhandling, da alle par ender med at aflevere specialet og få rimeligt gode karakterer. Men spørgsmålet er, om de hver især nødvendigvis bliver klogere på den andens udgangspunkt?

\section{Hygge og humor som medieringspraksis}

Tre ud af fire par udtrykker, hvordan humor spiller en vigtig rolle i deres samarbejdsproces. Hygge og humor styrker de centripetale tendenser i parrenes dialog og faciliterer deres gode relation. Der både hygges, grines og bages under lydrefleksionerne, og parrene arbejder bevidst med at skabe hjemlig hygge på forskellige måder, for eksempel gennem inddragelse af stearinlys, musik, kaffe og kage. Sanne og Jeanett beskriver, hvordan de "sørger for at skabe nogle gode omgivelser for os selv", og hvordan faglige problemer kræver en ekstra kop kaffe, som Sanne siger:

Og det tæenker jeg egentligt sådan hjœelper på vores skriveproces og at vi altid lige starter dagen med, nu henter vi lige kaffe. Nu er det kritisk, ja vi henter lige en kop kaffe mere.

Hyggestunder kan beskrives som en slags medieringspraksis og klangbund, der gør det muligt for parrene at opretholde den gode stemning, tale om og nærme sig en konstruktiv dialog om de spændinger og uoverensstemmelser, som opstår i skriveprocessen, som når de, 
som Sanne og Jeanett udtrykker det. "bliver lidt uvenner". De har fx et forskelligt forhold til, hvordan og hvornår de bruger tid på specialet. Sanne beskriver i det første interview, hvordan Jeannet godt kan "scette hende lidt af og overtage opgaven en lille smule", hvilket betyder, at hun kan:

få dårlig samvittighed over ikke at arbejde mere på opgaven eller bidrage mere til opgaven, fordi jeg holder fri, når Jeannet gerne vil arbejde videre, men det der også er i det er, at du kan godt lide at pusse-nusse lidt omkring det. Du hygger dig lidt med at arbejde videre, hvor jeg egentligt gerne vil hjem og slå hjernen fra.

Der er således en spænding mellem den måde, som parret hver især arbejder på, og i udsagnet ovenfor udviser Sanne en forståelse for denne forskel og kan desuden formulere, hvad den betyder for hende. Og bliver spændingen for stor, fortæller parret, at de løser den " ved at gå ned i Brugsen og købe en Dancake og så er alt godt igen". Hyggen bidrager til at lægge låg på de udfordringer, der opstår undervejs, da de står i kontrast til og kan forstyrre en god hyggestund. Hyggen og den fælles humor er med til at skabe og opretholde et fælles og indforstået "vi", som er afskærmet fra omverden i deres fortælling.

\section{Parskrivernes dialog med omverdenen}

\section{Separate verdener}

Omverden og alle dens krav udfordrer den tosomhed, som parrene plejer i specialeprocessen. For alle par gælder det, at de har svært ved og ikke tid til at rumme nye og uforudsete krav, udfordringer eller sociale forventninger. Som beskrevet i den første del af analysen får parrene dækket både deres personlige og faglige behov i samværet med skrivemakkeren. Parrene holder sig hjemme, og ingen af dem har specialepladser på universitet, da de ikke er velegnet til samtale mellem to parter. Karin og Anne, som bor sammen, beskriver, at det "fungerer bare bedst, at vi bare kan satte os her og tage en lille pause, hvis vi har brug for det og sådan."

I parrenes samarbejde omkring specialet er der fokus på harmoni og fælleshed og dermed gennemgående en vægtning af den centripetale tendens mod enhed og et entydigt vi. Det er i mødet med hverdagslivets krav og familien, at der opstår spændinger mellem de faglige stemmer, som fordrer, at der må knokles igennem for at blive kandidat, og på den anden side de sociale, mere personlige og familierelaterede stemmer. Stemmer, som sætter normer for acceptabel adfærd i forhold til, at man planlægger fødselsdage, som man plejer, går til fester, arbejder ved siden af specialet, henter børn tidligt, når man nu alligevel ikke har et rigtigt arbejde. For alle par er det en udfordring gennem hele specialeprocessen at lukke op for de faglige stemmer og ned for, hvor meget hverdagslivets stemmer og krav må fylde.

For at mediere denne spænding mellem modsatrettede krav vælger Maja og Irene at rejse langt væk sammen for at skrive, og når de er hjemme, længes de efter at gøre det igen. Når man er i udlandet, kan man ikke samtidigt stille op som mor, hustru eller veninde. Karin og Anne vælger at tage i sommerhus, mens de andre par forsøger at klare forhindringerne hjemme. I den sidste refleksion beskriver Lotte, hvordan hun har haft svært ved at slå til som veninde, og hvordan hendes venner ikke forstår, hvad det vil sige at skrive speciale. Som hun udtrykker det: "De lever i deres verden og jeg lever lige lidt i min og så ses vi til sommer".

Sanne og Jeanett kommer begge fra ikke-akademiske hjem, og de giver udtryk for, at ingen af deres forældre forstår, hvad de laver. Dermed er deres relation til familien under interviewe- 
ne karakteriseret ved et fravær af forståelse for det, der fylder allermest for dem. Som i Lottes beskrivelse bliver der også for dem tale om to separate verdener, de ikke oplever kan indgå i en dialog med hinanden.

\section{Kontakten til medstuderende og vejleder}

Fælles for alle par er, at de har valgt ikke at være aktive i fælles specialeseminarer, som ligger, efter de er kommet i gang med deres speciale. Som Karin bemærker, er det svært at finde "overskud" til at sætte sig ind i andres opgaver, og Anne supplerer med, at "man er så fokuseret på sit eget, at egoistisk set, så er man lidt ligeglad med, hvad deres handler om." Den faglige sparring med medstuderende opleves ikke som tilfredsstillende, da man - som Karin udtrykker det: "ikke opererer inden for samme emne (...) [så] får man heller ikke noget ud af det [peerfeedback'en]", og hun fortsætter med at sige, at parret heller ikke bruger feedback fra de andre: "Vi bruger jo kun det, vi har fået af vores vejleder."

Parrene inviterer altså ikke medstuderendes stemmer ind i deres fælles læreproces, ligesom de heller ikke ser en pointe i selv at indgå i en dialog med de andres projekter. Parrene oplever, at de har nok i deres faglige samarbejde. De giver endvidere udtryk for, at de jo bare kan tage kontakt til deres medstuderende, hvis der er noget de er i tvivl om.

Fordi parrene ikke møder op til de kollektive specialeaktiviteter, bliver kontakten til vejlederen central. Parrene beskriver, hvordan de igennem kandidatstudiet og i deres dialog med medstuderende har erfaret, at det er meget forskelligt, hvad vejlederne lægger vægt på. Karin og Anne beskriver, hvordan der har været

Forskellige indgangsvinkler og forskellige vejledninger og forskellige ting, man har faiet at vide og derfor har vi ogsa voeret meget specifik pa at sige, at vi holder os til det, [vejleder] har sagt, fordi det er det, som vi har faiet at vide, er rigtigt

Fordi det er så forskelligt, hvad de forskellige vejledere lægger vægt på, siger Maja og Irene undervejs i processen

at det er vigtigt at man som vejleder giver, hvad man ønsker som vejleder, så vi ikke skal gaette os til hver vejleder, fordi det er så forskelligt, hvad vejleder ønsker af en opgave.

I deres brug af vejlederen har flere af parrene som Maja og Irene et ønske om at få meget konkrete svar og bliver frustrerede, når de ikke får dem men i stedet møder et krav om selv at skulle reflektere over mulige svar. Igen som tidligere ser vi, hvordan parrenes måde at gå til skriveprocessen kan virke noget instrumentel og målrettet. Irene og Maja kritiserer tidligere vejledning for at være meget "flyvsk", og Maja mener, det "voesentlige" er få at vide, "hvad der er rigtig og forkert i ens skriveproces [...] og hvordan det skal voere". Sanne og Jeanett er også kritiske over vejledning, som de oplever som "mindre konkret." Når vejlederens svar har været "hvad giver mening-agtigt", så vil de hellere bare have et tilsagn fra vejlederen på, at det er ok det, som de skriver. De beskriver også, hvordan "vi har skulle argumentere rigtig meget for vores valg overfor vejlederen", og de opfatter dette som et tegn på, at vejlederen måske ikke har været det bedste "match". I deres sidste refleksion kobler de dog "den ukonkrete vejledning" sammen med, at de er blevet mere selvstændige gennem specialeprocessen, idet Sanne siger:

[...] hvis vi ikke var selvstcendige i forvejen, så havde det nok vaeret svoert at komme igennem processen. Men vi er også blevet selvstæendige, for vi har fået lidt ukonkret vejledning, så vi er også blevet nødt til... 
I deres søgen efter klare svar ses det, hvordan den centripetale tendens dominerer, og der lukkes ned for nysgerrigheden på en mulig flerstemmighed og den læring, den kunne facilitere. Endvidere synes parrenes tidligere oplevelser med medstuderende og vejledere at bidrage til, at de holder sammen 'mod de andre' (vores formulering), som de enten ikke (hvis det er studerende) kan lære så meget af, eller (hvis det er vejledere) ikke rigtig kan stole på giver dem retningslinjer, de kan bruge fremadrettet.

I vejledningen kan der derfor også opstå udfordringer, når parskrivernes fælles opfattelser møder kritik fra vejlederen. I Lottes og Silles vejledningsforløb er vejlederen kritisk overfor deres måde at skrive på og råder dem til at kontakte en skrivevejleder. Dette råd kolliderer tydeligvis med parrets selvforståelse af deres skrivekompetencer. Der opstår således en spænding mellem den måde, de i fællesskab opfatter kvaliteten i det, som de sammen producerer, og det som vejleder opfatter som kvalitet. Vejleders forstyrrelse af deres selvopfattelse betyder, at de bliver mere sammentømrede og føler sig misforståede. Lotte indikerer, at vejleders kritik er et udtryk for manglende forståelse og dårlig kommunikation i den sidste refleksion, når hun siger:

...at vi har ikke rigtig haft samme forståelse for tingene, vores vejleder og os. Jamen det har noget med kommunikationen at gøre.

Parret går så langt som til at beskrive, hvordan de oplever, at vejlederen er mere personlig end faglig i sin kritik, og det ved de ikke, hvad de skal stille op med - til at begynde med. Ved at reagere følelsesmæssigt på kritikken, kan de afvise den som personlig og ikke faglig (lignende spændinger omkring symmetri-asymmetri i individuel vejledning beskrives fx af Grant og Vehviläinen (Grant, 2008; Vehvilâinen, 2009)). Eksemplet ovenfor illustrerer igen, hvordan den centripetale tendens får konsekvenser for deres læring og manglende udvikling af den kritiske refleksivitet i skriveprocessen, som er kendetegnet for akademisk arbejde (Nordentoft \& Jensen, 2017). Til sidst i deres dialog kommenterer Sille dog alligevel "Men det er helt ok at gå i panik og det er faktisk også den proces man loerer mest af".

Sammenfattende viser interviewmaterialet en tendens til, at parrene trækker sig fra alternative eller modstridende stemmer, der opleves som forstyrrende. Set fra parrenes perspektiv kan man sige, at omverdenen heller ikke har megen plads til dem. Fysisk er der ingen specialepladser, der er anvendelige for dem; ingen forståelse fra familie; vejledningsformer, som de ikke oplever er målrettet til deres behov. Disse træk i det, som omverdenen (ikke) tilbyde er sandsynligvis med til at styrke de centripetale tendenser i parrets dialog med omverdenen, så de bliver skubbet hen imod at blive en lukket enhed, hvor de kommunikerer med sig selv og hinanden.

\section{Diskussion}

Flerstemmighed kan være en kim til læring (Bakhtin, 1981; Phillips, 2011b), og vi har undersøgt, hvordan flerstemmigheden har manifesteret sig i parrenes møde og samarbejdsproces med henblik på at indfange, om og hvordan de oplever at lære af hinanden. Vores undersøgelse viser, at den centripetale tendens er fremherskende i parrenes koordinering mellem deres forskelle, således at der er en foretrukken bevægelse hen imod en monologisering, som indbefatter forsøg på at reducere flerstemmig betydningsdannelse til en entydig stemme. Parrene taler glidende og ubesværet sammen, tilpasser sig og bygger videre på hinandens udsagn i deres turtagning, som søger mod at skabe konsensus i samtalen. Tilsyneladende bliver effekten af den anerkendelse og bevidsthed, som parrene udviser om hinan- 
dens styrker og deres klare rollefordeling, at de lukker ned for en eksplicit og verbal udforskning af deres magtforhold og spændinger frem for at åbne op for og være nysgerrig på disse forhold.

Når talen drejer sig om parrenes forskellige stemmer, så understreger parrene gentagende og næsten i samme åndedrag -, hvor meget de har tilfælles. På den ene side kan man i en Bakhtinsk forståelse sige, at parrene udviser en etisk funderet sensitivitet, anerkendelse og respekt overfor de stemmer, som de hver især bringer ind i dialogen, hvor parret ikke 'finalizer' eller determinerer hinanden, men udviser en respekt og vilje til at samarbejde, der har kunnet bære det tidsmæssige og faglige pres, det er at skrive et speciale. På den anden side kan man sige, at de netop underkender (potentielle) forskelle ved at fremhæve det fælles. Måske betyder det nære og emotionelle forhold og tidsmæssige pres, parrene er underlagt, at der ikke eksisterer en åbenhed overfor den andens potentiale for at være en anden eller indtage en anden rolle end den, som allerede er tilskrevet i lyset af parrenes samarbejde gennem hele kandidatforløbet (Frank, 2005).

Den fælles stemme - eller det fælles 'vi' -, som parrene konstruerer i deres fortællinger, kan betegnes som en fælles diskursiv platform, der forstærker de studerendes stemmer og deres deltagelse samt indflydelse i den faglige vejledning. Den eneste anden stemme, som parrene inddrager i deres arbejdsproces, er vejlederens stemme. Og dette forhold virker spændingsfyldt. Tilsyneladende styrker parrenes fælles ' $\mathrm{vi}^{\prime}$ den centripetale tendens i dialogen med vejlederen, og denne tendens kan siges at være en slags værn mod vejleders kritiske feedback. Forholdet mellem de centripetale og centrifugale tendenser i parrenes relation med vejlederen har således didaktiske implikationer for, hvordan vejlederen tilrettelægger sin vejledning.

På den ene side lærer parrene noget væsentligt og akademisk relevant ved at skrive og arbejde tæt sammen. De må håndtere forskellige stemmer, forhandle og metakommunikere og træffe en række valg både individuelt og i fællesskab, hvis specialet skal i hus. At skrive speciale sammen i par indeholder dermed også et stort potentiale i forhold til at udvikle en høj grad af selvstændighed, et begreb der indtager en central rolle i forståelsen af specialets funktion (Jensen, 2018). På den anden side er det at skrive speciale sammen i par ikke nødvendigvis entydigt selvstændighedsfremmende, hvilket den tilsyneladende fastlåste rollefordeling og dialogernes centripetale tendenser peger på, hvor de spændinger, der kunne udforskes og skabe ny viden i den dynamiske vekselvirkning mellem de to tendenser lukkes ubesværet ned. Parrene kan virke næsten instrumentelle og i hvert fald pragmatiske i deres måde at fordele arbejdsopgaver og håndtere skriveprocessen på.

Under analysen af interviewmaterialet er det blevet tydeligt for os, hvor kompliceret og potentielt sårbar en situation, vi har sat parrene i med vores metodiske tilgang. Netop fordi de studerende viser sig at være så tæt forbundne, at de indgår i en symbiotisk relation, kan det være svært for dem at forholde sig til spørgsmål, som potentielt kan kompromittere deres samarbejde og relation. Måske derfor taler parrene i interviewmaterialet så meget mere om lighed end forskellighed, ligesom de konsekvent iscenesætter forskellighed som komplementær og ikke forstyrrende. Disse forhold rejser spørgsmål om, hvilken betydning det har haft for vores undersøgelse, at alle parrene var nære venner inden de startede med at skrive deres speciale. Måske det medfører, at de er mere konsensussøgende og centripetale i deres dialog end specialemakkerere der ikke i forvejen var venner, ville være? Er det mon typisk for specialemakkere, at de er venner i forvejen? 
Ved at foretage semi-strukturerede interviews med de studerende hver for sig vil man opnå en anden indsigt i de individuelle oplevelser af at arbejde i et par, og det er muligt, at de studerende i denne type interviews i højere grad også ville tale om forskelle end ligheder. Med en interviewer til stede vil det også være muligt at spørge mere specifikt til evt. forskelle. Med en kombination af individuelle interviews og parrefleksioner ville man kunne forsøge sig med at identificere diskrepanser mellem det individuelle og det forhandlede fælles. Men da vores fokus har været at undersøge, hvordan parrene beskriver deres samarbejde i deres dialog sammen med hinanden med afsæt i Baktins dialogbegreb, finder vi den valgte metode mere velegnet. Dertil kommer, at vores socialkonstruktivistiske udgangspunkt implicerer, at de analytiske fund må ses i lyset af den situerede kontekst, de er blevet til i, og at de derfor ikke bliver mere sande eller valide af en analyse på tværs af forskellige former for data. I en vejledningsdidaktisk kontekst er det også en pointe, at det netop er parret og det forhandlede "vi", vejlederen møder i vejledningsrummet, og ikke to individer. Afslutningsvis er der behov for flere undersøgelser, som sætter fokus på, hvordan forskning i parspecialer kan kvalificeres - herunder didaktisk forskning, som kan belyse, hvordan vejledningen kan tilrettelægges, og tage højde for vekselvirkningen mellem parrets faglige og personlige dynamikker i skriveprocessen. Ligeledes mangler der forskning om, hvordan strukturelle forhold såsom fysiske og virtuelle læringsrum kan bidrage til at skabe et frugtbart specialeforløb for parskrivere.

\section{Konklusion}

Studerende, som skriver sammen i par, udvikler både faglige og processuelle kompetencer, da de må forhandle synspunkter og træffe en række faglige og personlige valg sammen. Deres læringsproces er spundet ind i en løbende dialogisk forhandling af deres relation og position i lyset af de krav og forventninger, som de møder fra hinanden og omverdenen. Disse forhold kan øge deres selvstændighed, men det er også en sårbar og spændingsfyldt proces, som kan betyde, at parskrivere fastholder hinanden i prædefinerede roller. Tosomheden indebærer derfor en risiko for, at parret lukker ned fremfor at undersøge den flerstemmighed og de spændinger, som i en Bakhtinsk forståelse er en forudsætning for læring.

\section{Referencer}

Andersen, H. L. \& Jensen, T. W. (2007a). Specialevejledning-rammer og roller: En universitetspcedagogisk undersøgelse. København: Samfundslitteratur.

Andersen, H. L. \& Jensen, T. W. (2007b). Vejledernes reaktion på retningslinier for vejledning. Dansk Universitetspoedagogisk Tidsskrift, 3, 20-28.

Bakhtin, M. M. (1981). The Dialogic Imagination. Four Essays. Austin \& London: University of Texas Press.

Bengtsen, S. (2012). Didaktik og idiosynkrasi. En undersøgelse af vejledningssamtalen på universitetet med fokus på forholdet mellem fagligt og personligt indhold. (Ph.D.). Aarhus Universitet, Aarhus.

Bengtsen, S., Mathiasen, H. \& Dalsgaard, C. (2015). Net-based guerilla didactics. In T. Fossland, H. Mathiasen, \& M. Solberg (Eds.), Academic Bildung in Net-based Higher Education. London \& New York: Routledge. 
Bengtsen, S. \& Nørgård, R. T. (2018). Didaktiske implikationer og principper ved global online inter-universitetsundervisning og hotseat tutorials. Kognition og Paedagogik, 108, 6883,

Berger, R. (2015). Now I see it, now I don't: researcher's position and reflexivity in qualitative research. Qualitative Research, 15(2), 219-234. doi:doi:10.1177/1468794112468475

Boud, D. \& Lee, A. (2005). Peer learning' as pedagogic discourse for research education. Studies in Higher Education, 30(5), 501-516.

Buber, M. (2004). I and Thou. London: Continuum.

Charmaz, K. (2014). Constructing grounded theory. London: Sage.

Cryer, P. (2006). The Research Student's Guide to Success. Berkshire: Open University Press.

Dalgaard, L. G., Johannsen, L. V., Kristiansen, M. \& Bloch-Poulsen, J. (2013). Differences as a potential vehicle of organizational development? Co-researching-on-action. In M. Kristiansen \&J. Bloch-Poulsen (Eds.), Participation and power : In participatory research and action research (Vol. 3, pp. 199-228). Aalborg: Aalborg Universitetsforlag.

Degn, L. \& Sørensen, M. (2015). From collegial governance to conduct of conduct: Danish universities set free in the service of the state. Higher Education, 69, 931-946. doi:10.1007/s10734-014-9814-1

Dysthe, O., Samara, A. \& Westrheim, K. (2006). Multivoiced supervision of Master's students: a case study of alternative supervision practices in higher education. Studies in Higher Education, 31(3), 299-318. doi:10.1080/03075070600680562

Frank, A. (2005). What is dialogical research and why should we do it? Qualitative Health Research, 15(7), 964-974.

Grant, B. M. (2008). Agonistic struggle master-slave dialogues in humanities supervision. Arts and Humanities in Higher Education, 7(1), 9-27

Hvass, H. \& Heger, S. (2018). Brugbar peer-feedback. Instruktion og træning, før de studerende selv skal give og modtage. Dansk Universitetspœedagogisk Tidsskrift, 13(25), 59-70.

Jensen, H. N. (2010). 'Det lukkede rum'. En dør på klem til specialevejledning. Dansk Universitetspoedagogisk Tidsskrift, 8, 17-22.

Jensen, H. N. (2015). Opgave- og skrivevejledning i klynger: Håndbog for undervisere og vejledere på videregående uddannelser. Frederiksberg: Samfundslitteratur.

Jensen, T. W. (2018). Det danske universitetsspeciale - topografi, tekster og tendenser. Aarhus: Aarhus Universitetsforlag.

Macbeth, D. (2001). On "Reflexivity" in Qualitative Research: Two Readings, and a Third. Qualitative Inquiry, 7(1), 35-68. doi:10.1177/107780040100700103

Nordentoft, H. M., Hvass, H., Mariager-Anderson, K., Bengtsen, S. S., Smedegaard, A. \& Warrer, S. D. (2019). Kollektiv Akademisk Vejledning. Fra forskning til praksis. Aarhus: Aarhus Universitetsforlag. 
Nordentoft, H. M. \& Jensen, M. E. G. (2017). "En usleben diamant": Video i udviklingen af masterstuderendes kritiske refleksivitet. Dansk Universitetspoedagogisk Tidsskrift, 12(23), 71-86.

Nordentoft, H. M. \& Olesen, B. R. (2014). Kommunikation i kontekst. København: Munksgaards Forlag.

Nordentoft, H. M., Thomsen, R. \& Wichmann-Hansen, G. (2013). Collective academic supervision: a model for participation and learning in higher education. Higher Education, 65(5), 581-593.

Nørgård, R., Toft-Nielsen, C. \& Whitton, N. (2016). Playful teaching between freedom and control. Exploring the magic circle in higher education. Paper presented at the Exploring Freedom and Control in global higher education, Newport, UK.

Pedersen, N. F., Albrechtsen, C. \& Jensen, T. W. (2013). Mobilapplikationers potentiale til understøttelse af specialeprocessen. Tidsskriftet Loering og Medier (LOM), 6(10).

Phillips, L. (2011a). Med forskel som forandringskraft : en introduktion til dialogisk kommunikationsteori. In P. Almlund \& N. B. Andersen (Eds.), Fra metateori til kommunikation (pp. 152-183). København: Hans Reitzels Forlag.

Phillips, L. (2011b). The Promise of Dialogue. The dialogic turn in the production and communication of knowledge. Amsterdam: John Benjamins Publishing Company.

Sarauw, L. L., \& Madsen, S. R. (2016). Studerende i en fremdriftstid. Prioriteter, valg og dilemmaer set $i$ lyset af fremdriftsreformen. Aarhus: Aarhus Universitet, DPU.

Vehvilâinen, S. (2009). Problems in the Research Problem: Critical Feedback and Resistance in Academic Supervision. Scandinavian Journal of Educational Research, 53(2), 185-201. doi:10.1080/00313830902757592 